\title{
At the Crossroad of Cultures: Education and Identity of Hungarian Deaf Learners in Romania
}

\author{
Emese Belényi ${ }^{1}$ \\ Recommended citation: \\ Belényi, E. (2019). At the Crossroad of Cultures: Education and Identity of Hungarian Deaf Learners in \\ Romania Central European Journal of Educational Research, 1(1), 68 - 79.
}

\begin{abstract}
Deaf people living in ethnic-national minority situation form a social group whose members have multiple cultural backgrounds. Starting from interpretations which are viewing the deaf child as a member of a distinct cultural and linguistic minority, I studied the education of Hungarian deaf pupils in Romania graduating from the Hungarian Special School in Cluj/Kolozsvár/Klausenburg, with particular regard to the relationship between formal and informal language use in school, communication culture and identity. Methodologically the research is based on life path interviews with Hungarian Deaf Special School graduates, family case studies of two or three generation deaf families and structured interviews with experienced educators. The research results reveal that the educational practice of the concerned educational institution strengthens the pupils' identity awareness and sense of belonging to the Hungarian nation in two distinct, still interconnected ways: on the one hand, through oral language acquisition, nursing the oral Hungarian language skills, and on the other hand through cultivating the Hungarian Sign Language embedded in the deaf culture within the learner community. Nowadays, the conditions and modalities of exercising this role are changing in several respects. The positive educational effects achieved so far can be reinforced and strengthened by educational policies based on the recognition and cultivation of cultural diversity, in all its complex and multifaceted manifestations, including the peculiar needs of ethnic minority deaf learners.
\end{abstract}

Keywords: deaf education; deaf culture; ethnic minority deaf, linguistic socialization, identity

\section{Introduction}

Until relatively recently, deafness was seen as simply a physical impairment: the absence of hearing (Butler, Skelton \& Valentine, 2001; Lane, 1997). In the past, much discrimination against deaf people was based on the assumption that they were in fact people without language (Davis, 2007). This approach ignored the fact that deafness is an unique kind of disability. From sociological and anthropological perspective, deafness, unlike other disability types, works as a linguistic and cultural communities forming factor. According to Tajfel (1978), cultural communities acknowledge that certain socially constructed group characteristics with specific cognitive content distinguish them from their social surroundings. In this regard, deaf community is not just one group of people with disabilities among others, but also a linguistic and cultural minority, whose members use sign language as a primary means of communication, behave in a similar manner and share similar beliefs. Deafness, as a state of being, requires on the one hand the adaptation of the society to the specific (social, educational, psychological, communication) needs of the deaf people, while on the other hand it is a phenomenon which provides the core identity of a certain group of people. According to Padden (1989) deaf community can be defined as the totality of languages, experiences, values and forms of contact which are characteristic for the deaf.

${ }^{1}$ Partium Christian University; belenyi.emese@partium.ro 
Today, disability centred outlooks oriented towards the compensation of hearing loss are step by step replaced by interpretations based on bilingual or even multilingual approaches, which are viewing the deaf child as a member of a distinct cultural and linguistic minority (Higgins \& Liberman, 2016), having at its core the use of sign language. This shift of paradigm presents a special importance for educational policies in the light of the fact that current discussions in the area of inclusive education stress the necessity for schools to develop equitable responses to diversity if all students are to be active and participating learners (Booth et al., 2000; Black-Hawkins, 2002; Florian, 2005; Humphrey et al., 2006). Appreciation of diversity moves learning communities away from the notion of normalization, which promotes 'sameness', and views difference as a negative attribute.

In devising teaching strategies based on recognition of cultural diversity aimed at deaf pupils, it is necessary to take into account that similarly to the hearing society, the inner structure of the deaf community is not homogeneous. Its members belong to a number of ethnic or linguistic communities - majority or minority - and this inner diversity cannot be ignored when we examine the development of deaf identity. Deaf people belonging to different nations communicate with each other in their respective national sign language, which is also a unique language, similarly to the oral language of that nation.

National minority is another type of minority cultural community, „, group of citizens of a State, constituting a numerical minority and in a non-dominant position in that State, endowed with ethnic, religious or linguistic characteristics which differ from those of the majority of the population, having a sense of solidarity with one another, motivated, if only implicitly, by a collective will to survive and whose aim is to achieve equality with the majority in fact and in law" (Deschénes, 1985: 24).

In the case of deaf belonging to ethnic-national minorities, there is a coincidence, a combination of the two mentioned types of culturally rooted disadvantage, which is generating multiple exclusions. First, within the society based on the hearing culture, they form a deaf cultural minority using the sign language as the most important mean of intra-community communication. Second, as ethnicnational minority members, they differ culturally and linguistically from the members of the deaf community belonging to the dominant ethnic-national community. Third, as deaf, they represent a marginal group also within the ethnic-national minority to which they belong.

The notion of bilingualism, when referring to the linguistic-cultural needs of the ethnic-national minority deaf learners, may be therefore, misleading (Ohna, 2003), as these learners are in fact in a situation of dual bilingualism. In this context, linguistic and cultural diversity can be efficiently incorporated into educational strategies to promote their education and social inclusion by acknowledging that deaf pupils, similarly to their hearing peers can have different backgrounds, family languages and cultural affiliations, and everyone has a fundamental right to live their identity under favourable conditions (Leigh \& Crowe, 2015).

Today the opportunity of ethnic Hungarian Deaf children in Romania to study in the special school in their native language is only partially secured, being available exclusively in the first eight classes of the special school and in only one educational institution within the country. To those parents who refuse residential separation from their children, the only other available option is to choose one of the Romanian special schools, which offer education exclusively in Romanian oral language and opportunities for the informal acquisition of Romanian Sign Language only. The part of the picture is also the fact that vocational educational for deaf is available exclusively in Romanian language, so for the graduates of the Hungarian primary special school for deaf there is no possibility to learn a profession in the special vocational school in their native language. In the Romanian language special vocational school the dominant language of peer student informal communication is the Romanian Sign Language. 


\section{Research design and Methods}

In the context outlined above, this paper aims to reveal the opportunities to use identity as a fundamental resource in a specific context linked to a particular type of minority. I shall discuss the situation of deaf people born to the Hungarian minority ethnic-national community in Romania. Specifically, my attention focused on the graduates of the Kozmutza Flóra School for Deaf in Cluj/Kolozsvár/Klausenburg, with Hungarian teaching language, the only special deaf education institution in Romania with this kind of linguistic educational offer. The central objective of my research is to find out the effects of the influencing factors and conditions which have an important impact on the process of educational inclusion and identity development of ethnic minority Hungarian deaf learners, focusing on the following main research questions:

Q1 How the socialization into deaf culture and the pursuit of native ethnic-national identity are interrelated within the formal and informal educational environments and practices of the special school?

Q2 What are the effects of the formal and informal learning environment within the Hungarian minority language special school with regard to the deaf identity and national identity development of the deaf children and their further processes of linguistic and cultural socialization?

In view of these questions, I formulated the hypothesis that the Hungarian oral language knowledge of pupils and their familiarity with Hungarian sign language gained in the special school both act as important identity markers shaping the national identity of deaf pupils belonging to the Hungarian minority community in Romania. Based on the claims made in the specialist literature concerning the education of ethnic minority hearing children (Gúti \& Szépe, 2006; Göncz, 2004) I supposed that the teaching language of the special school is an important factor in shaping the national identity of deaf pupils belonging to the Hungarian minority.

In planning my research strategy, I started from the assumption that the processes of social exclusion and inclusion, as well as the process of identity formation and identity changes accompany the whole life-paths of individuals. That is why any analysis should include all important stages and social settings of a person's life-path. In order to achieve this, I considered that the method of life-path research (Kohli, 2007) would be the most adequate option, as it would facilitate the focus on those crucial life events and turning points which have had a major influence on the identity of ethnic minority deaf individuals. Over the course of research, the following methods and techniques have been applied:

a) Life path interviews with ethnic Hungarian deaf individuals and their ethnic Romanian spouses (30 persons) selected on the basis of relevant typological criteria, in order to reveal their deeper motives and personal ways of reaching life-shaping decisions, the subjective means of experiencing key events occurred in one's life, and their influence on identity.

b. Family case studies, in order to allow the tracing of identity transfer within the family in a greater time horizon and its analysis in connection to the external factors and internal changes influencing family life.

c. As a complementary method, I conducted structured interviews with highly experienced educators from the Hungarian Special School. The problems addressed during the interviews concerned: past and current educational practices; parent educational options and motivations; relations between teachers, pupils, and parents; the deaf community within the special school; further study and vocational mobility opportunities.

\section{Results}

\subsection{Language Use and Deaf Identity in Special School}


When the deaf child reaches the school age, the most important stage of socialization is the special school (sometimes the integrated education form) and its pupil community (Harris-Beech 1995), where the child is spending most of its time (mostly residential boarding school in the context). The children of the deaf parents - the hearers too - acquire sign language as their mother tongue at early age, while the deaf children of the hearing parents learn sign language when they are in the schools for deaf.

It must be emphasized that pupils in special schools have learned and used sign language despite the fact that during the communist period formal school curriculum did not include sign language or sign language courses. In Romania, like in other countries in Europe, Deaf schools, driven by the "normalization" paradigm, concentrated unilaterally on oral education according to their formal educational program. The change of the regime after 1989 brought about a change in the attitude of the school's teaching body towards sign language as well, although in the first years most of the teachers refused to use the sign language, despite the fact that deaf students used the sign language between each other throughout the school history. The reason for this teacher attitude was not only the pedagogical beliefs that teachers acquired during their academic formative years, but also the lack of their sign language knowledge.

"When I was in school twenty years ago, most of the teachers did not sign at all with the children. Children learned sign language from each other and not from adults. We also learned it from children, from those few children born from deaf parents. Ever since I was here, there have always been teachers who support and those who oppose sign language. After a while, some of us managed to weigh the balance on the sign language side. Thus, the use of sign language has now been accepted, but the level of sign language knowledge of the teachers is low. The sign language is very important for acquiring oral language, a fact which everyone is now aware of. We use it, but as I have said, our opportunities are limited by the level of our knowledge"(T. P. educator of deaf, hereinafter T.P.).

Therefore, deaf children of hearing parents become familiar with sign language and deaf culture / community for the first time in the special school, mainly due to their informal pupil community linguistic socialization, due to the fact that this is the first time in their life that they encounter a deaf community using sign language and become its members. This language acquisition and cultural socialization, however, occurs spontaneously and inconsistently. They learn spontaneously from older peers, practice informally, and use it as a primary means of communication, which plays a decisive role in their spontaneous socialization process into deaf culture.

H. Z. When she was six years old, she came to the school of deaf and hard-of hearing. Here, she encountered the deaf culture with sign language communication for the first time in her life. In her weekly classes she also developed her lip-reading skills. She remembers that when her mother left her in the school of the deaf, it was very difficult to leave her departing parents, she was sad, sad, but that sadness did not last so long: she was soon overwhelmed by the world of her new companions, the world of deaf culture: "I just looked at it amazed, I did not know it, and yet it was so familiar. I've never seen this before and I've been extremely impressed since the first moment."

P. L. According to her, she was really astonished: a naive, still-full-hearted 6-year-old girl who is beginning to understand the world around her, her concrete, well-formed pictures of words, and the use of these forms to be used in linguistic contexts, as sign language sentences and her own thoughts, which she conveyed to the others, and also received interpretable answers. She had a lot of friends, she found somehow easier to make friends in the deaf school community, they did not look at each other with as much criticism as hearers do within their own communities. She had a wonderful time in this world, the years she spent in Hungarian Deaf School were very happy years. She had never felt lonely in those years.

Based on the above, we can conclude that the informal student community - albeit in a different direction from the formal education policy principles focusing on oral education - plays a decisive role in the deaf cultural community and linguistic socialization of deaf children. All this is consistent 
with the findings of studies conducted in the school environment of hearing students, which point out that among the effects of the school environment of great importance are the closeness and density of pupil peer relationships based on similarity of world views and norms, which create a sense of security of norms and thus helps the development of school career (Pusztai, 2003: 67).

"Hearing-impaired children born into hearing families, as different from those from the deaffamilies, had a lot of similarities within the group within socialization. Given that these children were diagnosed much later (only one of them was diagnosed with hearing loss before the age of two), and that the patterns of communication typical of the average hearing family in the case of these children showed very little success, in all cases the lack of communication skills was unquestionable. compared to age-appropriate expectations" (G. K, educator of deaf, hereinafter G.K.).

"With regard to the low final exam passage ratio among deaf students, this is partly due to the flaws of the school, but it is a fact that language development is significantly lagging behind in the case of our hearing impaired who typically received a hearing aid as late as at the age of three, and did not access early development. The level of an average 18-year-old hearing impaired in the United States who received hearing aid and development at early age aid, is the same as that of a hearing 10-yearold child. We do not have statistics for this, but it is not difficult to guess the level. So the miracle is that if an exceptional hearing impaired person succeeds in maturity exams "(T.P.).

This latter possibility is mostly realized when the favourable educational effects of an early family environment are accompanied by good residual hearing, strong motivation and desire to talk, which also feeds on the success stories, as in the following case.

$N . T$. is the only child of a family of hearing people. A beautiful-looking, very well-groomed girl who was a school student from kindergarten to 8th grade. She has a very good hearing experience, her speech is understandable to almost everyone. Almost oddly in the school's students' population, T is mostly talking and only secondly hearing impaired. Speaking loudly with classmates and schoolmates, the signals were assigned to the said content by adapting them to the elements of the spoken language.

"The truth is that the oral approach in a deaf school never becomes the means of primary communication. Everyone who is studying with us falls into such a unicorn system: if speech is not their strength, if they feel is more difficult to move the word than the hand, they will sign. They grow up to be constantly faced with the differences between people"(N. Z., educator of deaf).

Unlike children growing up in the hearing family, who are unlikely to be in contact with the sign language before entering school, children with deaf parents having sign language family communication background are more likely to experience continuity rather than discontinuity within Deaf School community.

"Children from the deaf family have a huge advantage, as they communicate effectively with their parents, in the early childhood there is a language that is available for the development of their thinking. Those from the deaf family are therefore in every respect advantaged. Differences can be demonstrated by test results, and I measured 20 years ago in our school with tests of analogy thinking among others"(P.T.).

D.R. 7-year-old preparatory class boy. A hard-boiled, sweetheart, almond-like and bait boy born to a hearing impaired family. Both her parents were students of the school: her father comes from a multi-generation deaf family, her mother's is hearing family. $R$ is a challenge-seeker, always inventing some new adventure that he usually seduces with a more naive companion, and these adventures rarely end up with inexcusable results. $R$ was a pre-schooler at the age of three and had a good reference treasure at that time. Although he is using a hearing aid, it is now clear that he prefers the sign language against loud speech, his speech is soft, dragged, 
and clearly embarrassed when called upon to speak. Mimicry is lively during signing, his movements are agile and slightly elaborate (not yet articulated in aesthetic sign language).

In cases where parents are experienced sign language users, simultaneously signing and oral communication can produce positive results, suggesting that there is still untapped potential in the combined use of sign language and spoken language. Under the influence of educational requirements, deaf children from deaf parents try to learn the oral language as a second language. Knowledge acquired in this way is perceived as enrichment in communication tools, but the primary cultural environment of their existence remains the deaf peer community and the spontaneously acquired sign language culture.

\subsection{Deaf Culture and National Identity}

In the absence of integrated education as a realistic alternative apart from exceptional cases, during the whole period of the communist regime, the Hungarian Deaf School in Cluj/Kolozsvarr/Klausenburg ensured the chance of surviving the Hungarian community of the deaf. The main factors of this process have been the role of the Hungarian, generally hearing, educators; the curriculum related to Hungarian culture; the practice and use of oral communication in the Hungarian language (lip reading, loud speaking, articulation, reading and writing) in the classroom and to some extent within the pupil community; the informal use of the Hungarian sign language as a primary means of communication with the companions; the relationship between the ethnically homogenous Hungarian student community, the Hungarian school and the Hungarian families of the students; parents' insistence on oral communication in Hungarian and the Hungarian identity of their child.

Hungarian identity also manifests itself embedded in deaf culture, through the use of Hungarian Sign Language, or rather, of its regional version within the pupil community of the Hungarian deaf school. In the same time, the results of my interviews confirm that in addition to the Hungarian Sign Language, the mother tongue oral and written communication tools acquired in the special school also have had an important role in identity development, helping pupils to better approach and improve the quality of their relationship with their parents and the quality of their attachment found in native language culture. The following detail of an interview with a school educator will help to illuminate the role of Hungarian sign language, more precisely of its version used in the Hungarian Deaf School, in its complexity and in its dynamics over generations.

"According to our experience, the gradual acquisition of the sign language and the unbelievable power of the actively used language at the time of entering the institution and the experience of belonging to a group in which information and interactions are equally accessible to all members, do not require facilitation, promptness, and increase the sense of identity in the child. It does not only mean that when attending preschool age, he/she adds at self-introduction that he/she is hearing impaired, but more importantly, also means engaging in intra-group engagement, communicative urge, reciprocity in raising the awareness and shaping power of a new socialization milieu for the family, in which the child is confidently present, in many ways, with greater involvement than in everyday life"(G. K).

In the same time, the results of my interviews confirm that in addition to the Hungarian Sign Language, the mother tongue oral and written communication tools acquired in the special school also had an important identity development functions, helping pupils to better approach and improve the quality of their relationship with their parents and the quality of their attachment found in native language culture. Although they usually spent vacations only in their parental environment, these few weeks still proved to be important in strengthening their identity roles, despite the fact that the oral communication methods were not exercised with great pleasure and the level of selfexpression skills was typically low. Their primary cultural community sense of belonging remained attached to the Deaf School, primarily to its pupil community. 
P.S. When he went home from school during vacation, his parents did not even try to use the sign language he had learned at school, so he tried to read their mouths using the methods learned in the school. His parents had never been willing to use sign language communication with him, used exclusively oral communication with their hands behind their backs.

D.E. "I grew up in a hearing family, I forgot completely in my vacation what I learned from my companions. Actually, I was really looking forward to going back to school. "

H. Z. did not use the sign language at home during the long vacation, so he reportedly forgot a lot before the beginning of the new school year. His relationship with his parents was very good, though he communicated with them with oral speech and lip reading. His parents spoke slowly, and he did not even try to get his family members to use the sign language during his school years.

"A significant part of our hearing impaired children communicate with their own family at such a low level that we frequently need to interpret between parents and their children. Only a few hearing parents know the sign language. There is no really a place for them where to learn. The Deaf Association is weak, there are no sign language lessons like in Hungary. There was an attempt two years ago, but they did not continue. In some cases, parents are spontaneously creating a sort of "family of sign language" with their small children and children start to teach signs to their parents"(T.P.).

In addition to the oral communication, or rather as an organic part of it, hearing parents generally consider important the lip reading skills of their children, not just for the quality improvement of the relationship between parent and child, but also for the transmission of the national identity.

"For Hungarian hearing parents, it is important that their child, though bilingual, be a Hungarian deaf. The primary significance of Hungarian schools resides not in the differences in sign language, because it is hardly relevant for the hearing impaired, rather it resides in learning to read and write in Hungarian. The word-reading image in Romanian and Hungarian is very different"(P.T.).

As we have already had occasion to address it, the relationship between deaf parents and deaf children is fundamentally different in many respects than in the family of hearing parents, and this also applies to the child's school years, albeit in a partially different manner. In contrast to the children of hearing parents, the children of deaf parents are born into the deaf culture, so in their case oral speech development in kindergarten or school age can be built on a more solid basis in their case, which is the already acquired language-visual expression and thinking. Thus, oral communication skills, being reinforced by the effects of family communication environment, can play an important complementary and consolidating role in strengthening the ethnic-national identity linked to the mother tongue. The following family case study provides a closer look at the operation mechanism of this process.

P. L. originates from a Hungarian mother tongue hearing family, but he did not study at the Hungarian Deaf School, so he knows the Hungarian sign language only because her deaf children have shown her. It's not used at home. The sign language socialization of the two children has taken place very early in the family, in Romanian Sign Language. When they came to the Hungarian special school, they were taught in Hungarian oral expression and loud speech, and also became familiar with the Hungarian Sign Language from their fellow students. To reinforce this, they use Hungarian oral language at home, with their father, but accompanied by the Romanian Sign Language previously acquired within the family. Even though they communicate with their parents in Romanian Sign Language, Hungarian signs did not disappear without a trace from their communication repertoire. During my several week long observation in different relational situations, I have found that the two brothers are communicating with each other in Hungarian Sign Language and the Hungarian oral language learned in school. The explanation for this resides in the fact that pupils in special 
schools spend much more time with each other in the school compared with the hearing children of their age. Thus the educational role of the special school is greatly enhanced.

\section{Discussion}

If we accept as a starting point that children in ethnic-national minority status needs multilingual development, it is first of all necessary to clarify what languages they learn and use in their home childhood family, school, adult family life, deaf community and the larger society; based on this information we can formulate the concrete goals of language development; and finally, in order to be successful in the process, it is necessary to develop multi-faceted partnerships with the children's families, communities and their assistants. All this requires clear language learning policy concept and planning, adequate educational set up, family assistance and legislation.

The experience of different countries in this respect may present huge variations. From a linguistic-cultural perspective, if faced with the homogenizing policies of the ethnic-national majority, minority language usage appears to be a disadvantaging factor ( $\left.\mathrm{O}^{\prime} \mathrm{Neill}, 2013\right)$ and tends to be discouraged. A research in the United States has shown that the Spanish parents of deaf children there typically received the advice of using only English language combined with sign language in their communication with their children. In Australia, according to 2014 research results, English is also dominant in the communication relationship between ethnic minority parents and their deaf children. Parents who use only English in family communication typically feel that this language provides the most favourable conditions for their linguistic, cognitive, social, emotional development and professional experience (Crowe et al., 2014).

In contrast, another research exploring the same issue in the multicultural regions of Spain (Guiberson, 2013), where regional languages have a recognized status, has produced different results. $50 \%$ of the parents surveyed in the research have received a statement from a counsellor who advises them to communicate with their child in more than one language, and the proportion of those advised not to do so is only $36 \%$. This supports the fact that the institutional support of multicultural regions provides more favourable conditions for the diversity of ethnic-linguistic identities within the deaf population. Nevertheless, although many parents believe that multilingualism is accessible and useful to their children in practice, only a few deaf children become actually multilingual.

The case of Romania fits in a specific - and in certain respects contradictory - way in this picture. On the one hand, the interviews with the teachers of the Hungarian Special School confirm that this teaching institution, building on its centuries-old traditions, still plays a key role in maintaining the national and mother tongue identity of Hungarian deaf in Romania. However, the information gained during the interviews also highlights the fact that this role of the school is currently limited by several hindering factors, and the conditions and modalities for exercising this role are partly in the process of being transformed, to some extent weakened. Hereinafter, we summarize the effects of these factors briefly:

- The increasing migration of graduates to vocational schools in Hungary. According to our information, for instance, half of the students from one of the recent years of graduation are studying in vocational schools in Budapest. On the one hand, this powerful migration trend is related to the new opportunities following the change of regime (the EU accession of the two countries, the change of the Hungarian citizenship law) and the fact that special vocational education in Romania is still not available in Hungarian. Migration has controversial implications: while guaranteeing the survival of the Hungarian identity of migrants, in the same time tends to cut them off from their homeland Hungarian community, reduce the number of deaf people at home, and thus contribute to the increase of the assimilation pressure within the predominantly Romanian local deaf communities.

- The increasing tendency of assimilation is reflected in the fact that an increasing proportion of ethnic Hungarian deaf (31\% of those surveyed) live in ethnically mixed marriages. My research results support the fact that in ethnically heterogeneous families the possibilities of Hungarian sign language 
/ oral language use are very limited and there is an increasing chance that children born to such families (who are hearing in $90 \%$ of cases) will embrace Romanian ethnic-national identity.

- Decreasing tendency in the number of the deaf population as a result of improved hearing care, due to the spread of cochlear implantation. This trend affects the deaf society in its entirety, and while it offers the deaf person a new perspective of integration, it results, however, in alienation from the deaf culture, and at the level of the deaf community is perceived as a numerical loss.

- The attraction of the Romanian Deaf School. This phenomenon does not only affect the children of deaf parents living in mixed marriages, but many of the Hungarian hearing parents living in homogenous marriages are also sending their children to a Romanian special school. Those parents residing far away from Cluj/Kolozsvár/Klausenburg who refuse residential separation from their children, have to choose one of the Romanian special schools. Such institutions are usually functioning in all the larger cities; however they offer education exclusively in Romanian oral language and opportunities for the informal acquisition of Romanian sign language only.

\section{Conclusions}

The results of my research confirm the validity of my hypothesis and underline the fact that to be a Hungarian deaf In Romania involves two aspects of minority existence: one is the attachment for the Hungarian minority culture, the other is the belonging to the language barrier quasi-free, transnational communication and socialization system of the Deaf World. Thus, the optimum development of personality is only possible in the unity of these two dimensions.

The educational experience of pupils who graduated from the Hungarian Deaf School demonstrates that socialisation into the deaf culture and the strengthening of the oral/ sign language Hungarian language identity are far from being mutually exclusive educational-educational outcomes; on the contrary, they are complementary. They are intended to form a bridge linking two closely related permanent roles and behaviours in the child's personality development.

The real possibility of enhancing opportunities resides therefore in inclusive solutions based on linguistic and cultural pluralism, which would presuppose the transformation of the whole education and social inclusion system. There is a need to establish a new legal and institutional framework which could provide a favourable social environment for the recognition and enhancement of the complex and multiple identities so much characteristic for ethnic minority deaf people.

Funding: This research received a grant from the HUNGARIAN ACADEMY OF SCIENCES, within the framework of the Homeland Grant Programme (2017/2018).

Acknowledgments: Part of the data for this research have been collected within the framework of the Doctoral Programme of Educational Sciences, Doctoral School of Human Studies, University of Debrecen.

Conflicts of Interest: The author declares no conflict of interest. The funders had no role in the design of the study; in the collection, analyses, or interpretation of data; in the writing of the manuscript, or in the decision to publish the results.

\section{References}

1. Black-Hawkins, K. (2002): Understanding school cultures: developing participation. PhD thesis, The Open University, 2002.

2. Booth, T., - Ainscow, M.- Black-Hawkins, K. - Vaughn, M. és Shaw L. (2000): Index for inclusion: Developing learning and participation in schools. Bristol: Centre for Studies on Inclusive Education, 2000.

3. Butler, R., Skelton, T. és Valentine, G. (2001): Language barriers: Exploring the world of the deaf. Disability Studies Quarterly, 21(4), 42-52.

4. Crowe, K., Fordham, L., Mcleod, S., \& Ching, T. Y. (2014). 'Part of Our World': Influences on Caregiver Decisions about Communication Choices for Children with Hearing Loss. deafness $\mathcal{E}$ education international, 16(2), 61-85. 
5. Davis, L.J. (2007): Deafness and the Riddle of Identity The Chronicle: 1/12/2007.

6. Deschénes , J. (1985): Proposal concerning a definition of the term „minority" submitted by Mr. J. Deschénes. Doc. E/CN.4/Sub. 2/1985/31, 14.05.1985, p.24..

7. Florian, L. (2005): Inclusive practice. In: Topping K. and Maloney S. (eds.) The Routledge Falmer reader in inclusive education London, Routledge Falmer, 2005, 29-40.

8. Harris, M. \& Beech, J. (1995): Reading development in prelingually deaf children. In K. Nelson K.és Reger Z. (szerk.) Children's Language Volume 8. Englewood Cliffs, NJ, Lawrence Erlbaum Associates, $181-202$.

9. Higgins, M., \& Lieberman, A. M. (2016). Deaf Students as a Linguistic and Cultural Minority: Shifting Perspectives and Implications for Teaching and Learning. Journal of Education, 196(1).

10. Humphrey, N. - Bartolo, P. - Alle, P. - Calleja, C. - Hofsaess, T. - Janikova, V. - Mol Lous A.- Vilkiene, V.és Wetso, G. (2006): Understanding and responding to diversity in the primary classroom: An international study. European Journal of Teacher Education 29, no. 3: 305-318.

11. Göncz L (2004): A vajdasági magyarság kétnyelvűsége: nyelvpszichológiai vonatkozások. Szabadka: MTT.

12. Guiberson, M. (2013). Survey of Spanish parents of children who are deaf or hard of hearing: Decisionmaking factors associated with communication modality and bilingualism. American Journal of Audiology, 22(1), 105-119.

13. Gúti E. \& Szépe Gy. (2006): A szivárvány-koalíció nyelvpolitikája (Nyelvpolitika alulnézetben) In: Tóth Sz. (ed..) Hatalom interdiszciplináris megközelítésben. Szeged: Szegedi Egyetemi Kiadó, 111-128.

14. Kohli, M. (2007): The Institutionalization of the Life Course: Looking Back to Look Ahead. Research in Human Development, 4. 2007/3-4., 253-271

15. Lane, H. (1997): Why the Deaf are Angry? In: Gregory, Susan és Hartley, Gillian M.(szerk.) Constructing Deafness. London and New York: Pinter, 117-120.

16. Leigh, G., \& Crowe, K. (2015). Responding to cultural and linguistic diversity among deaf and hard-ofhearing learners. In: and Marschark M. and Knoors H (eds.) Educating deaf learners: Creating a global evidence base, Oxford: Oxford University Press, 68-91.

17. Ohna, S. E. (2003): Education of deaf children and the politics of recognition. Journal of deaf studies and deaf education, 8(1), 5-10.

18. O'Neill, F. (2013): Making sense of being between languages and cultures: a performance narrative inquiry approach. Language and Intercultural Communication, 13(4), 386-399.

19. Padden, C. (1989): The Deaf Community and the Culture of Deaf People. In: Sherman Wilcox (szerk.) American Deaf Culture. Silver Spring, Maryland: Linstok Press.

20. Pusztai G. (2003): Hitvalló közösségek rejtett társadalmi funkciója. Magiszter (Csíkszereda) 1:(1) 65-70.

21. Tajfel, H. (1978): The Social Psychology of Minorities. London: Minority Rights Group.

(C) 2019 by the authors. Submitted for possible open access publication under the terms and conditions of the Creative Commons Attribution (CC BY) license (http://creativecommons.org/licenses/by/4.0/). 